Correction

\title{
Correction: Samad, N., et al. Behavioral and Biochemical Effects of Mukia madrespatana Following Single Immobilization Stress in Rats. Medicina 2020, 56, 350
}

\author{
Noreen Samad ${ }^{1, *}$, Amna Ali ${ }^{1}$, Farzana Yasmin ${ }^{2,3}$, Riaz Ullah ${ }^{4}$ and Ahmed Bari ${ }^{5}$ \\ 1 Department of Biochemistry, Bahauddin Zakariya University, Multan 60800, Pakistan; \\ amnaali394@gmail.com \\ 2 Department of Biomedical Engineering, NED University of Engineering and Technology, \\ Karachi 75270, Pakistan; farzanayasminpk@yahoo.com \\ 3 Department of Food Engineering, NED University of Engineering and Technology, Karachi 75270, Pakistan \\ 4 Department of Pharmacognosy (MAPPRC), College of Pharmacy, King Saud University, \\ Riyadh 12372, Saudi Arabia; rullah@ksu.edu.sa \\ 5 Central Laboratory, College of Pharmacy, King Saud University, Riyadh 12372, Saudi Arabia; \\ abari@ksu.edu.sa \\ * Correspondence: noreen.samad@bzu.edu.pk
}

\section{Change in Funding part:}

We would like to change the funding part of paper [1] from:

Funding: The authors extend their appreciation to the Research Supporting Project Number (RSP2019/110), King Saud University Riyadh, Saudi Arabia for financial support.

to the correct version, as follows:

Funding: The authors extend their appreciation to the Research Supporting Project Number (RSP2020/110), King Saud University Riyadh, Saudi Arabia for financial support.

We apologize for any inconvenience caused to the readers.

Conflicts of Interest: The authors declare no conflict of interest.

\section{References}

1. Samad, N.; Ali, A.; Yasmin, F.; Ullah, R.; Bari, A. Behavioral and Biochemical Effects of Mukia madrespatana Following Single Immobilization Stress in Rats. Medicina 2020, 56, 350. [CrossRef] [PubMed]

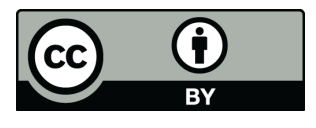

